\title{
OS FUNDAMENTOS DA RUPTURA DE RELA- ÇÓES DIPLOMÁTICAS ENTRE O BRASIL E A GRÃ-BRETANHA EM 1863: "A QUESTÃO CHRISTIE” (II).
}

\section{(Conclusão) .}

Neste meio tempo, entretanto, ocorreu um segundo incidente que tornou-se base das queixas futuras. Indicando que os tribunais brasileiros não mereciam ser reconhecidos pelas nações "civilizadas" o Govêrno Inglês propôs que um oficial britânico participasse das investigações do caso Prince of Wales. A recusa brasileira a esta proposta foi tomada como um insulto à Marinha Britânica.

Quando Russell em setembro ouviu falar, pela primeira vez, do naufrágio, ordenou ao Almirante Warren que mandasse um oficial ao local para acompanhar o inquérito (97). Vereker, entretanto, aconselhou não crer que a presença do oficial pudesse ser útil a menos que fôsse o resultado de "instruções do Govêrno Brasileiro" e o projeto foi temporàriamente abandonado (98). O bom julgamento de Vereker, entretanto, não foi reconhecido por seus superiores.

Em março de 1862, Christie resolveu assumir a responsabilidade de pedir a Warren que mandasse um vaso de guerra ao Rio Grande com um oficial de alta patente e importância, capaz de assistir Vereker no inquérito que talvez fôsse instituído (99). Simultâneamente, informou ao Ministro do Exterior brasileiro que enviara tal oficial para acompanhar

"qualquer inquérito que pudesse ser instaurado, se tal cooperação fôsse agradável ao Govêrno Imperial" (100).

\footnotetext{
(97). - Russel a Ballie, Foreign Office, 6 de setembro de 1861. N.० 5, Ibid., p. 131. Ver também Baillie a Russel, Rio de Janeiro, 5 de novembro de 1861. N.0 12, ibid., p. 134 .

(98). - Vereker a Baillie, Rio Grande, 2 de dezembro de 1861, incluído em Ballle a Russell, Rio de Janeiro, 6 de janelro de 1862 . N.o 20, ibid., p. 142; Warren ao Almirante, Forte, no mar, 23 de dezembro de 1861, incluído em W. G. Romaine a Layard, Almirantado, 4 de fevereiro de 1862. N.0 21, ibid., p. 142 .

(99). - Cf. Russell a Baillie, Forelgn Office, 8 de fevereiro de 1862. N.० 22, ibiđ., p. 143, com Christie a Warren, Petrópolis, 17 de março de 1862, inclúdo em C. Paget a Layard, Almirantado, 3 de junho de 1862. N. ${ }^{\circ}$ 30, lbid., pp. 156-157.

(100). - Christie a Taques, Petrópolis, 17 de março de 1862, incluído em Christle a Russell, Rio de Janeiro, 5 de maio de 1862 . N.o 27, ibid., p. 152.
} 
O envio do oficial, então, não teve a aprovação do Govêrno Brasileiro como sugerira Vereker. Isto não pode, certamente, provar que Christie procurava algum incidente que pudesse apoiar seus ataques ao Govêrno Brasileiro mas é improvável que desconhecesse a probabilidade dos brasileiros rejeitarem a oferta:

O Capitão-Almirante do Forte, Thomas Saumarez, chegou ao Rio Grande logo em seguida, levando consigo um bote armado para cruzar a entrada do pôrto (101). A 6 de abril Sauniarez e Vereker viajaram 180 milhas através da lagoa dos $\mathrm{Pa}$ tos a Pôrto Alegre para falar pessoalmente com o Presidente. Acreditavam que

"a presença de um dos navios de Sua Majestade tão. próximo do centro da província daria grande fôrça... e aumentaria o pêso de nossas reclamações" (102).

E' importante notar que Vereker informou o presidente em sua primeira nota estar o barco de Saumarez armado com cinqüenta e um canhões (103).

Vereker insistiu em ser Saumarez reconhecido como ocupando posição especial na investigação (104). Mas alegou o Presidente não ter recebido ordens sôbre o assunto, não podendo assim reconhecer o capitão como representante oficial (105). Finalmente Vereker concordou com a decisão do Presidente e disse que Saumarez estaria presente ao inquérito numa qualidade não oficial (106) .

Numa parte do memorändum escrito por Vereker sôbre as conversações, lê-se

"o Cônsul... observou que dependeria inteiramente da descrição de Sua Excelência sôbre se ordenaria inquérito imediato ou esperaria instruçôes".

(101). - Orders addressed to Capitain Saumarez, Forte, Montevidéu, 31 de março de 1862, incluídos em Paget a Layard, Almirantado, 3 de junho de 1862. N.o 30 , ibid., p. 157.

(102). - Saumarez a Warren, Forte, Montevidéu, 21 de abril de 1862. incluído em Paget a Laéard, Almirantado, 3 de junho de 1862. N.o 30, ibid., p. 157.

(103). - Vereker a Rocha, Pôrto Alegre, 6 de abril de. 1862, incluído em Vereker a Russell, Rio Grande, 14 de abril de 1862 . N.o 26, ibid., p. 147.

(104). - Vereker a Russell, Rio Grande, 14 de abril de 1862 . N.0 26, ibid., p. 146.

(105). - Memorandum of a conversation teld on the 7 th of April, 1862..., incluída em Vereker a Russell, Rio Grande, 14 de abril de 1862. N.o ; 26, ibid., p. 149; Rocha ao Govêrno Imperial, Pôrto Alegre, 10 de abril de 1862, extrato. Relatório, 1863, Anexo I, p. 15.

(106). - Vereker a Rocha, Sheldrake, Pôrto Alegre, 8 de abril de 1862, incluído em Vereker a Russell, Rio Grande, 14 de abril de 1862. N. ${ }^{\circ} 26$, "Cor" respondence", Sessional Papers, LXXIII, 150. 
'do Govêrno Central (107). E' esta a única vez, no memorandum inteiro, que a palavra "imediato" é usada; ainda que, numa quase subseqüente referência ao caso afirmou-se que o Presidente concordou com um inquérito imediato. O Presidente tinha, ao contrário, sugerido que a presença de navios de guerra britânicos causariam com mais facilidade a fuga dos culpados do que qualquer demora por parte das autoridades (108) .

Desde que até 17 de abril não havia ainda sido instituído o inquérito, Saumarez deixou o Rio Grande, sem ter executado seus propósitos. Vereker decidira que a continuada presença de Saumarez implicaria estarem os inglêses

"esperando a conveniência das autoridades provinciais", e acrescentou "a reclamação feita pelo Govêrno de Sua Majestade foi recebida com cortesia insuficiente, ou dizendo melhor, pouco respeito" (109).

Saumarez no seu retôrno comunicou ào Almirante Warren ter o Presidente da província prometido "um inquérito imediato e completo" - - o que talvez não seja uma declaràção surpreendente pois Saumarez não compreendia o português (110). Warren não perdeu a ocasião para declarar que deixar um oficial como Saumarez esperando dez dias sem resultado nenhum havia sido "grande falta de cortesia" (111). Christie ao informar todo o caso aos seus superiores consultou como deveria agir com respeito a esta falta de cortesia.

(107). - Memorandum of a conversation teld on the 7th of April, 1862..., incluída em Vereker a Russell, Rio Grande, 14 de abril de 1862 . N.o 26, ibid., p. 149; sôbre a exatidão do memorandum, cf. Vereker a Russell, Rio Grande, 14 de abril de 1862. N.0 26, ibid., p. 146, com Luís José Carvalho Melo Matos a Vereker, Pôrto Alegre, 23 de abril de 1862. Relatório, 1863, Anexo I, p. 28.

(108). - Rocha ao Govêrno Imperial, Pôrto Alegre, 10 de abril de 1862, extrato, Relatório, 1863, Anexo I, pp. 15-16.

(109). - Vereker a Russell, Rio Grande, 16 de abril de 1862. N.0 31, "Correspondence" Sessional Papers, 1863, LXXIII, 158; Saumarez a Vereker, Sheldrake, Rio Grande, 16 de abril de 1862, incluido na carta acima, ibid., p. 159; Vereker a Saumarez, Rio Grande, 16 de abril de 1862, incluído em Christie a Russell, Rio de Janeiro, 7 de maio de 1862. N. ${ }^{\circ} 28$, ibid., $p$. 155; Saumarez a Warren, Forte, Montevidéu, 21 de abril de 1862, incluído em Paget a Layard, Almirantado, 3 de junho de 1862 . N.o 30, ibid., p. 158.

(110). - Saumarez a Warren, Forte, Montevidéu, 21 de abril de 1862, incluído em Paget a Layard, Almirantado, 3 de junho de 1862. N.0 30, ibid., 158; Vereker teve que traduzir para Saumarez: Memorandum of a conversation teld on the 7th of April, 1862, inclufdo em Vereker a Russell, Rio Grande, 14 de abril de 1862 . N. 26 ; ibid., p. 149.

(111). - Warren a Christie, Forte, Montevidéu, 23 de abril de 1862, incluído em Christie a Russell, Rio de Janeiro, 7 de maio de 1862. N.o 28, ibid., p. 154. 
Russel insistiu em um "inquérito apropriado" no caso Prince of Wales, estando um oficial britânico presente (112).

Em julho, Christie iniciou uma longa correspondência com. Abrantes sôbre o caso Saumarez que durou até outubro. Começa com fortes queixas pelo fato de ter sido deixado Saumarez esperar tanto tempo e ter que se retirar antes de qualquer inquérito ser iniciado. Acentua também a exigência de Russell. dã presença de um oficial inglês, não esclarecendo se êste desejava um oficial naval (ou simplesmente um representante do Govêrno Britânico) nem se o reconhecimento oficial fizesseparte do pedido (113) .

Em resposta às notas de Christie, Abrantes salientou que a presença do oficial naval de modo nenhum poderia influenciar o curso da justiça desde que os tribunais brasileiros estavam completamente aptos para resolver o problema. Desde que o Presidente da Província não tinha marcado data definitiva para o inquérito proposto, não havia campo para queixas sôbre qualquer demora. Além disso, se Saumarez aceitou uma posição particular, dificilmente poderia esperar que as autoridades levassem seus planos em consideração (114). Em conseqüência, não havia desrespeito nas ações dos oficiais brasileiros para com a Marinha Britânica (115).

Abrantes também salientara que o maior obstáculo ao início do inquérito tinha sido a presença dos navios inglêses.. Isto levara a população a sentir que o curso da justiça era resultádo da pressão britânica e sua oposição, dever patriótico (116). Christie replicou não entender como

"poder-se-ia ver alguma ameaça na presença de dois pequenos navios" (117).

Mas Abrantes salientou não ser o tamanho dos navios, e sim 0 que êles representavam - uma grande e poderosa nação - o que estava em questão. A presença dêsses navios só

(112). - Christie a Russell, Rio de Janeiro, 7 de maio de 1862 . N.o 28, ibid., p. 154; Russell a Christie, Foreign Office, 4 de junho de 1862 . N.o 29, ibid., p. 156.

(113). - Christie a Abrantes, Rio de Janeiro, 16 de julho de 1862, incluído em Christie a Russell, Rio de Janeiro, 20 de julho de 1862. N. ${ }^{\circ} 43$, ibid., p. 175 .

(114). - Abrantes a Christie, Rio de Janeiro, 6 de agôsto de 1862. Relatório, Anexo I, p. 68 .

(115). - Abrantes a Christle, Rio de Janeiro, 6 de setembro de 1862. Tbid., pp. 84-86.

(117). - Christie a Abrantes, Rio de Janeiro, 22 de agôsto de 1862, inclúío em Christie a Russell, Rio de Janeiro, 23 de agôsto de 1862 . N. ${ }^{\circ} 49$, "Correspondence", Sessional Papers, LXXIII, 202. 
poderia ser interpretada como uma tentativa do govêrno britânico para mostrar sua influência e simbolizar seu poder (118).

Christie mudou então o campo de suas críticas ao Govêrno Brasileiro por não ter avisado ao Presidente da Província que um oficial naval inglês aí se apresentaria, de modo que a vinda de Saumarez fôsse esperada (119). Abrantes, por seu turno, perguntou se a ação de Christie, ordenando a ida de Saumarez ao Rio Grande, antes de receber resposta do Govêrno Brasileiro, não teria sido, também, uma grande falta de cortesia (120). Assim, para cada questão de Christie, Abrantes tinha respostá; o incidente não tinha os ingredientes necessários para propiciar oportunidade de querelas.

Christie estava inteirado, desde o comêço da correspondência, do solo movediço no qual se apoiava e já havia sugerido a Russell que talvez êste pudesse modificar ou retratar seus pedidos (121). Agora, no principio de novembro, interrompeu a correspondência com o Ministro do Exterior Brasileiro, tecendo comentários a Russell, dizendo, que o Govêrno Brasileiro queria cobrir seus erros no caso com "sofismas". Teve também a temeridade de se referir ao tom em que eram vasadas as notas brasileiras, que para êle não pareciam "muito convenientes" (122). Christie não mais precisava do caso Saumarez, porque apareceu outro que se adaptava muito mais às exigências britânicas.

A 17 de junho três oficiais, incluindo o capelão, do navio inglês Forte, fizeram, em roupas civis, uma recreativa excursão ao popular recanto das montanhas da Tijuca, perto do Rio de Janeiro. De acôrdo com seu depoimento, caminhavam pacificamente ao longo do caminho que levava ao ponto onde se encontrava a condução que os levaria de volta ao Rio. Quando passavam pelo destacamento policial a sentinela dirigiu-se a êles ameaçadoramente. Como nenhum dos oficiais falasse português, o capelão, que ia à frente, perguntou em espanhol: "Que quer o senhor?" A essa inocente pergunta, a sentinela bateu no

(118). - Abrantes a Christie, Rio de Janeiro, 6 de setembro de 1862 . Relatório, 1863, Anexo I, pp. 84-86.

(119). - Christie a Abrantes, Rio de Janeiro, 22 de agôsto de 1862, incluído em Christie a Russell, Rio de Janeiro, 23 de agôsto de 1862. N.o 49, "Correspondence", Sessional Papers, 1863, LXXIII, 202.

(120). - Abrantes a Christie, Rio de Janeiro, 6 de setembro de 1862, Relatório, 1863, Anexo 1, pp. 84-86; Taques a Christie, 19 de abril de 1862. Ibid., p. 24.

(121). - Christie a Russell, Rio de Janeiro, 20 de julho de 1862. N.0 43, "Correspondence", Sessional Papers, 1863, LXXIII, 174.

(122). - Christie a Russell, 6 de novembro de 1862. N.0 64, ibid., pp. 225 e 226. 
Feito do capelão com a coronha de seu fuzil e o tocou com a ponta de sua baioneta, ao mesmo tempo em que gritava pela guarda. A última atendeu prontamente, aprisionando todos três, com brutalidade e os fechou na prisão. O oficial da guarda perguntou-lhes os nomes e graduação, mas em seguida rasgou 0 papel no qual escreveram a resposta. Ainda que certamente entenderam, por intermédio de um intérprete, que eram oficiais, - ainda assim os brasileiros recusaram-se a soltá-los. Na manhã seguinte, ordenaram-lhes ir para o Rio a pé. Ofereceram-se para pagar uma condução, mas lhes foi dito que, mesmo sendo oficiais, não passavam de simples prisioneiros (123).

O relato brasileiro dos acontecimentos foi bem diferente, A 2 de julho foram interrogados quase todos os envolvidos no caso e de seu testemunho emergiu a seguinte história. Os oficiais tinham bebido e deixaram o hotel onde jantaram, cantando alegremente( 124). Antes de atingir o destacamento policial, nolestaram uma mulher e tentaram desmontar um cavaleiro (os oficiais sustentaram que, ao contrário, até "demos alguns cobres aos pretos") (125). Ao atingir a casa de guarda o capelão subiu uns degraus e perguntou à sentinela: "Que figura faz você aí?" A sentinela mandou- $\emptyset$ andar, mas, ao invés disso, o capelão disse que os soldados brasileiros eram uns miseráveis e serviam apenas para serem pegados pelos pés e cobertos de pontapés. Nisso tentou agarrar as pernas da sentinela. Éste bateu-lhe com a coronha de seu fuzil, fixou a baioneta para defender-se dos outros dois que avançavam com suas bengalas e chamou a guarda: Os três inglêses lutaram ferozmente, sendo necessária fôrça para submetê-los e encarcerá-los. $\mathrm{Na}$ prisão proferiram vociferações, abusaram dos móveis, causando um distúrbio geral. O oficial da guarda perguntou-lhes seus nomes, porém êstes fingiram não entender português e re-

(123). - G. Clemenger a Saumarez, Forte, Rio de Janeiro, 20 de junho de 1862; Eliot Pringle a Saumarez, Forte, Rio de Janeiro, 20 de junho de 1862; Geoffrey Hornby a Saumarez, Forte, Rio de Janeiro, 20 de junho de 1862, tudo incluído em Christie a Russell, Rio de Janeiro, 7 de agôsto de 1862. N..$^{\circ}$, ibid., pp. 178-180; Reply of Clemenger..., Pringle, and Hornby..., incluído na mesma carta. N.o 45, ibid., pp. 182-184; Clemenger, Pringle e Hornby a Warren, Forte, Rio de Janeiro, 16. de agôsto de 1862, incluído em Christie a Russell, Rio de Janeiro, 23 de agôsto de 1862. N.0 48, ibid., pp. 191-193.

(124). - Interrogatórios... Relatório, 1863, Anexo I, p. 106; cf. com Deposition..., incluído em Christie a Russell, Rio de Janeiro, 23 de agôsto de 1862 . N.0 48, "Correspondence", Sessional Papers, 1863, LXXIII, $190 \mathrm{n}$.

(125). - Interrogatórios... Relatório, 1863, Anexo I, pp. 103-105; Clemenger, Pringle e Hornby a Warren, Forte, Rio de Janeiro, 16 de agôsto de 1862, incluido em Christie a Russell, Rio de Janeiro, 23 de agôsto de 1862. N.o 48, "Correspondence", Sessional Papers, LXXIII, 192. 
cusaram-se a responder. Foi então chamado um intérprete, que sabia falar alemão. Mas os oficiais continuaram a insultar os brasileiros e a recusarem-se a dizer os seus nomes. Numa ocasião, quando solicitados a dizer nomes e graduação, um dêles escreveu alguma coisa num pedaço de papel, mas quando o entregava, o capelão tomou-o e rasgou-o. Finalmente o oficial dá guarda disse que as únicas ordens que recebera referentes ao tratamento de prisioneiros, era levá-los a pé para o Rio (126).

Os oficiais britânicos, não só negaram tudo isso, mas afirmaram que, embora nenhum dêles usasse uniforme, um usava um colete naval, com botões em forma de âncoras, para os quais êles chamaram a atenção dos brasileiros (127). Christie fêz disso ponto de apôio para suas queixas, o que levou um crítico a dizer que a Grã-Bretanha estava pronta a ir

"à guerra, porque as autoridades de um país estrangeiro não compreendiam o que um guarda-marinha queria dar a entender ao apelar para seus botões" (128).

A sua chegada ao Rio os oficiais, sem dúvida ainda apontando para seus botões, foram jogados no que êles chamaram

"um antro desagradável... entre todos os desordeiros da cidade" (129).

Lá permaneceram 2 horas até a chegada do cônsul, que os removeu para uma prisão melhor, aonde foram tratados de um modo mais condizente com a sua posição, ali permanecendo até ao dia seguinte, quando foram soltos. Nunca foram proferidas acusações contra êles (130). Mais tarde, o Chefe de Polícia confirmou que ao receber o relato dos acontecimentos da casa da guarda e ao verificar

(126). - Interrogatórios... Relatório, 1863, Anexo I, pp. 102-107.

(127). - Ibid., p. 105; Clemenger, Pringle e Hornby a Warren, Forte, Rio de Janeiro, 16 de agôsto de 1862, inclúfio em Christie a Russell, Rio de Janeiro, 23 de agôsto de 1862. N.0 48, "Correspondence", Sessional Papers, 1863, LXXIII, 193.

(128). - Christie a Russell, Rio de Janeiro, 23 de agôsto de 1862. N.o 48, "Correspondence", Sessional Papers, 1863, LXXII, 186; Discurso de Robert Cecil (posteriormente primeiro Ministro Salisbury), Câmara dos Comuns, 6 de março de 1863. Hansard, XLXIX (1863), 1156.

(129). - Hornby a Saumarez, Forte, Rio de Janeiro, 20 de junho de 1862, incluído em Christie a Russell, Rio de Janeiro, 7 de agôsto de 1862. N.o 45, "Correspondence", Sessional Papers, LXXIII, 179.

(130). - Pringle a Saumarez, Forte, Rio de Janeiro, 20 de junho de 1862, inclúdo em Christie a Russell, Rio de Janeiro, 7 de agôsto de 1862 . N. ${ }^{\circ}$ 45 , ibid., p. 179 . 
"serem os atos praticados pelos oficiais meramente resultantes do estado em que se achavam na ocasiáo, determinei logo que os soltassem" (131).

Alegaram os britânicos que esta acusação de embriaguês foi feita pelos brasileiros apenas para

"dar côr às suas acusações falsas e esconder seu procedimento covarde" (132).

O acontecido logo tornou-se matéria de correspondência diplomática. A 24 de junho, Christie foi informado do caso pelo Almirante Warren. Referia-se êste ao caso como um "ultraje atroz" e "brutal" (133), e dizia ser, no seu modo de pensar, caso

"mais sério do que aquêle pelo qual recebeu, sob ameaça de fôrça, recentemente, em Montevidéu"

(cnde, provàvelmente, garantira o pagamento de indenizações. a súditos britânicos por danos causados durante as guerras da. última década") (134).

Christie não confiava muito no resultado do inquérito realizado pelos brasileiros. Acusou ter o retardamento dêste permitido aos soldados arquitetar uma defesa (135); e clamava ser o relato inteiro uma "história inventada" (136). Salientava o fato de ser a sentinela um homem da "mais baixa classe", o intérprete germânico um desconhecido e a brutalidade costumeira dos soldados brasileiros suficiente para explicar as: ações da sentinela (137). Mais tarde, Russell salientou, como:

(181). - Agostinho Luís da Gama a Sinimbú, Rio de Janeiro, 5 de julho de 1862. Relatório, 1863, Anexo I, p. 102.

(132). - Réplica de... Clemenger..., Pringle, e... Hornby, incluído em Christie a Russell, Rio de Janeiro, 7 de agósto de 1862. N.0 45, "Correspondence", Sessional Papers, 1863, LXXIII, 184.

(138). - Warren a Christie, Forte, Rio de Janeiro, 22 de junho de 1862, incluído em Christle a Russell, Rio de Janeiro, 7 de agosto de 1862 . N.o 45, ibid., p. 177.

(184). - Christie a Russell, Rio de Janeiro, 7 de agôsto de 1852 . N.o 45, ibid., p. 176; Juan E. Pivel Devoto e Alcira Ranieri de Pivel Devoto, Historia de la Republica Oriental de Uruguy (1830-1930). (Mońtevidéu, 1945), pp. 325-326.

(135). - Christie a Abrantes, Rio de Janeiro, 19 de agôsto de 1862, inclufdo em. Christie a Russell, Rio de Janeiro, 23 de agôsto de 1862. N.0 48, "Corrsepondence", Sessional Papers, 1863, LXXIII, 194.

(136). - Christte a Russell, Rio de Janeiro, 23 de agôsto de 1862. N.0 48, ibid., p. 186 .

(137). - Christie a Russell, Rio de Janeiro, 23 de agôsto de 1862 . N.o 48, ibid., p. 186; Reply to the Brazilian Memorandum on the questions of the officers of $H$. M. S. Forte, incluido em Christie a Russell, Rio de Janeiro, 23 de janeiro de 1863. N.० 3, "Further Correspondence respecting: 
uma das razões para ressentimento dos soldados brasileiros contra a Inglaterra as reclamações deșta no caso Prince of Wales (138).

Um incidente como o do Forte, era o que os inglêses estavam esperando. Logo a 22 de junho, dois dias depois dos oficiais serem libertados, Warren sugeria a necessidade de reparações (139) e a 6 de agôsto ainda repetia a mesma reclamação $(140)$. Christie provàvelmente já pensava em represália nos princípios de agôsto, pois fazia planos para conduzir o caso do Forte a uma solução antes do Almirante deixar o local (141). Christie sugeriu a Abrantes que o Brasil devia oferecer satisfações à Inglaterra antes de esperar pelo veredictum inglês (142). Neste meio tempo, sugeria a Russell os têrmos apropriados para qualquer pedido que fôsse iniciado: I. demissão do oficial da guarda; II. - punição da sentinela; III. - desculpas públicas por parte do Govêrno Brasileiro e IV. - censura pública ao Chefe de Polícia (143). Chegara à conclusão de serem estas as sugestões indicadas com a ajuda do Almirante Warren (144). Russell as apoiou quase palavra por palavra (145). A 8 de outubro escreveu que depois de ter estudado o assunto só podia

the Plunder of the Wreck of the British Barque 'Prince of Wales'; and the IIl - treatment of Officers of Her Majesty's ship 'Forte' ", Readex Microprint, ed. Edgar L. Frickson, British Sessional Papers, L-C, 26 de fevereiro de 1863 (3094), LXXIII, 283.

(138). - "Copy of Case Submitted, on Behalf of Her Majesty's Government, to the Arbitration of His Majesty the King of the Belgians, in the Case of the Officers of the "Fort(e)"", Readex Microprint, ed. Edgar L. Frickson, British Sessional Papers, L-C 26 de junho de 1863 (impressão ordenada pela Câmara dos Lordes em 29 de junho de 1863), LXXIII, 332-333.

(139). - Warren a Christie, Forte, Rio de Janeiro, 22 de junho de 1862, inclúdo em Christie a Russell, Rio de Janeiro, 7 de agôsto de 1862. N.0 45, "Correspondence", Sessional Papers, 1863, LXXIII, 177.

(140). - Warren ao Almirantado, Forte, Rio de Janeiro, 6 de agôsto de 1862, inclurdo em Romaine a Layard, Almirantado, 3 de setembro de 1862 . N.o 46, ibid., p. 185 .

(141). - Christle a Russell, Río de Janeiro, 7 de agôsto de 1862. N. ${ }^{\circ}$ 45, ibid., p. 176.

(142). - Christíe a Abrantes, Rio de Janeiro, 19 de agôsto de 1862, inclứdo em Christie a Russell, Río de Janeiro, 23 de agôsto de 1862. N.0 48, ibid., p. 194.

(143). - Christie a Russell, Rio de Janeiro, 23 de agôsto de 1862. N.0 48, ibid., p. 186.

(144). - Warren ao Almirantado, Forte, Rio de Janeiro, 8 de setembro de 1862, incluído em Romaine a Layard, Almirantado, 4 de outubro de 1862 . N.o 51, tbid,, p. 204.

(145). - Russell a Christie, Foreign Office, 8 de outubro de 1862. N.0 53, ibld., p. 207. 
"chegar à conclusão que a versão dada pelos três oficiais era a verdadeira, e que a defesa feita pelos brasileiros era indigna de crédito" (146).

Ainda que possamos duvidar de como as palavras de oficiais de uma só nação tivessem o monopólio da verdade, mesmo assim não se poderia de modo razoável esperar que Russell não confiasse nas palavras dos oficiais inglêses. Mas o pivot dc caso, mesmo como êles o contaram - uma vez que admitiam estar sem uniformes e nâc falar português -- é que tudo isso não era motivo suficiente para reclamações. Faz parte da natureza humana o fato de que onde existir jovens oficiais estrangeiros há sempre lugar para desentendimentos como êste, a maior parte dos quais poderiam ser transformados em incidentes, se assim o desejassem as partes interessadas. Pode-se suspeitar que o tratamento dado aos oficiais não foi assim tão rude nem tão conscientemente insultuoso para provocar represálias, a menos que houvesse outras fôrças provocando as ações britânicas (146a).

Em todo caso, o conflito entre a Inglaterra e o Brasil aproximava-se do seu climax. No mesmo dia em que fizeram as exigências acima com respeito ao caso do Forte, Russell dava a conhecer os têrmos pelos quais a Inglaterra dar-se-ia por satisfeita no que se referia ao naufrágio do Prince of Wales. Pedia compensações d osaque, uma vez que o Govêrno Brasileiro era

\section{"responsável pelas perdas causadas pelo procedi- mento culpável das autoridades".}

Mencionava a soma reclamada pelos proprietários do navio e dizia que se o Brasil admitisse o princípio, a Inglaterra aceitaria arbitragem para que a soma fôsse estabelecida (147). Ao mesmo tempo Russell instruia Christie e Warren para planejarem juntos possíveis represálias (148).

(146). - Ibid., p. 206 .

(146a). - De fato, em 1853 ocorreu um incidente com um Mr. Hale quase idêntico ao dos oficiais do Forte. Vide - Jeringham - a Limpo de Abreu, Rio de Janeiro, 24 de outubro de 1853. Legações estrangeiras, Grã-Bretanha, 1853, Arquivo Itamarati, 284-4-5; Sérgio Teixeira de Macedo a Limpo de Abreu, Londres, 7 de fevereiro de 1854. N.0 6, Legação Imperial ná Inglaterra, 1854, Arquivo Itamaratí, 217-3-8. Teixeira Macedo, o ministro brasiletro na Inglaterra temia que o incidente levasse à restauraça do juiz conservador.

(147). - Russell a Christie, Foreign Office, 8 de outubro de 1862. N.o 52, ibid., p. 206; cf. esta carta de Christie a Russell, Rio de Janeíro, 23 de agôsto de 1862. N.o 49, ibid., p. 195.

(148). - Russell a Christie, Foreign Office, 8 de outubro de 1862. N.o 54, ibid., p. 207; E. Hammond ao Almirantado, Foreign Office, 8 de outubro de 1862. N.0 55, ibid., p. 208. 
Christie, entretanto, não entregou estas notas imediatamente ao recebê-las, mas decidiu esperar pelos detalhes e natureza das represálias sugeridas. Respondeu que à vista da posição recentemente tomada pelo Govêrno Brasileiro, Russell poderia usar

"tom mais agressivo e talvez maiores exigências" (149).

Em princípio de dezembro, Christie recebeu ordens para represálias: Russell queria evitar de tôda forma qualquer ocasião que pudesse conduzir as fôrças armadas brasileiras a entrar em conflito com a Inglaterra (150). Uma vez que Warren estava preparado para represálias, Christie estava pronto a agir (151).

Dêsse momento em diante as relações entre a Inglaterra e o Brasil podem ser divididas em três períodos distintos. O primeiro, de 5 a 31 de dezembro foi de desenfreada agressividade por parte de Christie culminando com a ordem de represálias. O segundo, e também mais curto estágio da controvérsia anglo-brasileira, limitou-se à primeira semana do novo ano. Durante êsse periodo Christie assumiu conduta por deveras conciliatórias e o Govêrno Brasileiro acedeu às reclamações inglêsas e as represálias terminaram. O período final, dilatando-se até os princípios de julḩo, caracteriza-se pela agressividade brasileira, culminando com pedidos ao Govêrno Inglês que só poderiam terminar com a ruptura de relações. Os três estágios estudados em conjunto revelam o balançar do pêndulo entre o ultimatum britânico e a retaliação brasileira.

O primeiro período começou quando Christie endereçou três notas ao Ministro do Exterior brasileiro. Em duas delas quase repetiu por inteiro as instruções de Russell de 8 de outubro, com respeito aos casos do Prince of Wales e Forte, respectivamente (152). Na terceira pede resposta até 20 de dezembro, fazendo assim com que as três cartas em conjunto se transformem num ultimatum (153). Aparentemente, isto foi

(149). - Christie a Russell, Rio de Janeiro, 6 de novembro de 1862. N. ${ }^{\circ}$ 65, ibid., p. 230 .

(150). - Russell a Christie, Foreign Office, 8 de novembro de 1862.' N.o 62, ibid., p. 224.

(151). - Warren ao Almirantado, Madagascar, Rio de Janeiro, 7 de novembro de 1862, incluído em Paget a Hammond, Almirantado, 3 de dezembro de 1862. N.0 66, ibid., p. 231.

(152). - Christie a Abrantes, Petrópolis, 5 de dezembro de 1862, incluído em Christie a Russell, Rio de Janeiro, 15 de dezembro de 1862. N:0 70, ibid., pp. 233-234; e Christie a Abantes, 5 de dezembro de 1862, incluído na mesma carta, ibid., pp. 234-235.

(153). - Christie a Abrantes, Petrópolis, 5 de dezembro de 1862, incluído em Christie a Russell, Rio de Janeiro, 8 de dezembro de 1862 . N.0 68, ibid., p. 232. 
feito mediante pressão do Almirante Warren que não queria ficar, êle e seus homens, durante o verão no pôrto quente e. insalubre do Rio de Janeiro (154). A atitude de Christie nessa época é indicada por seu depoimento de que esperava

"trazer a lição agora ministrada, muitos benefícios para os interêsses britânicos no Brasil, e ensinar que o Govêrno de Sua Majestade, ainda que paciente e indulgente, não permitiria mesmo ninharias contra êle" (155):

Abrantes conseguiu estender o limite do prazo até o dia 29 e neste dia apresentou a resposta brasileira. Ainda que deplorasse fôssem adotadas represálias neste assunto tão trivial, - Govêrno Brasileiro negava-se a reconhecer a responsabilidade de que era acusado no caso do Prince of Wales; recușava-se a pagar indenizações aos proprietários do navio naufragædo e aos parentes da tripulação; mas, "se fôsse obrigado a ceder à fôrça" - pagaria sob protesto tudo que Christie ou seu govêrno exigissem. Com respeito aos oficiais do Forte, Abrantes declarou que não se submeteria aos pedidos inglêseș, achando mais honroso sofrer as conseqüências (156).

$\mathrm{Na}$ noite do dia seguinte, Christie escreveu sua resposta. Anunciou que o Almirante Warren começaria então as represálias, que eram, claro,

"dentro dos limites do estado de paz" e "um modo reconhecido entre as nações para se obter justiça" (157).

Esta nota foi entregue a Abrantes na manhã de 31 de dezembro. Warren havia enviado um navio na noite precedente e ao nascer da aurora enviou outro. Sem nenhum esfôrço, interceptaram todos os navios brasileiros que aproximavam ou

(154). - Christie a Russell, Rio de Janeiro, 8 de dezembro de 1862, extrato. N.o 68, ibid., p. 232; cf. Christie a Russell, Rio de Janeiro, 6 de novembro de 1862. N.0 65, ibia., pp. 230-231; ver também Christie a Russell, Rio de Janeiro, 24 de dezembro de 1862. N. ${ }^{\circ}$ 71, ibid., p. 237; e Christie a Abrantes, Rio de Janeiro, 30 de dezembro de 1862, incluído em Christie a Russell, Rio de Janeiro, 8 de janeiro de 1863, extrato. N.0 72, lbid., p. 254

(155). - Christie a Russell, Rio de Janeiro, 8 de dezembro de 1862 . N.0 68, ibid., p. 232.

(156). - Abrantes a Christie, Rio de Janeiro, 29 de dezembro de 1862 . Relatório, 1863, Anexo I, pp. 122-123.

(157). - Christie a Abrantes, Rio de Janeiro, 30 de dezembro de 1862, incluído em Christie a Russell, Rio de Janeiro, 8 de janeiro de 1863, extrato. N.0 72, "Correspondence", Sessional Papers, 1853, LXXIIr, 256. 
partiam do pôrto do Rio, levando-os para uma baía vizinha e conservando-os aí (158).

No dia seguinte ao comêço das represálias (primeiro de janeiro) percebe-se uma mudança no tom de Christie. O pêndulo começava a afastar-se da agressividade britânica. Christie escreveu a Abrantes que estava pronto,

"a considerar... qualquer proposta razoável... como, por exemplo, entregar-se tôdas as questões em disputa a um árbitro imparcial" (159).

No dia 3 do mesmo mês os diplomatas reuniram-se para traçar uma nota que fôsse aceitável para ambas as partes. Não é possível avaliar-se por documentos utilizáveis se esta mudança de atitude foi o resultado do susto de Christie ao ver suas ações o levarem tão longe, ou se impressionasse com a oposição demonstrada na cidade para com suas ações. Possìvelmente, foi o barão de Mauá que conseguiu fazer Christie tomar uma atitude mais razoável (159a). Em todo caso, dêste ponto em diante nota-se uma nova direção nas negociações.

As notícias sôbre as represálias iminentes causaram gran$\mathrm{d} \epsilon$ tumulto na cidade. Fizeram-se discursos na Bôlsa de Mercadorias. Christie recebeu notas ameaçadoras, o Govêrno Brasileiro colocou guardas na sua residência, e êle temia sair à rua. Ao se saber das primeiras represálias a comoção foi ainda maior. Christie declarou que tal excitação não tinha sido vista desde os dias do Aberdeen Act. O Imperador em pessoa falou ao povo em diferentes lugares da cidade, assegurando que a honra do Brasil seria salvaguardada (160). A polícia

(158). - Christie a Russell, Rio de Janeiro, 8 de janeiro de 1863. N.o 72, ibid., pp. 238-239; Christie a Warren, Rio de Janeiro, 30 de dezembro de 1862, incluído na carta acima. N.0 72, ibid., p. 256; Warren a Christie, Forte, Rio de Janeiro, 30 de dezembro de 1862, incluído na mesma carta. N.o 72, ibid., p. 257; Warren a Christie, Forte, 4 de janeiro de 1863, incluido na mesma carta. N. ${ }^{\circ} 72$, ibid., p. 266. Warren ao Almirantado, Forte, Rio de Janeiro, 8 de janeiro de 1863, e Orders addressed to Commander Henry, Forte, Rio de Janeiro, 30 de dezembro de 1862, ambas incluídas em Romaine a Hammand, Almirantado, 4 de fevereiro de 1863. N.o 75, ibid., pp. 273-274.

(159). - Christie a Abrantes, Rio de Janeiro, 1 de Janeiro de 1863, incluído em Christie a Russell, Rio de aneiro, 8 de janeiro de 1862 . N. ${ }^{\circ} 72$, lbid., p. 261.

(159a). - Mauá ao marquês de Olinda, 1 de janeiro a 3 de janeiro de 1863 . Arquivo MIP, Maço CXXXIII, Doc. 6346.

(160) . - Christie a Russell, Rio de Janeiro, 6 de janeiro de 1863, extrato. N.o 72, ibid., pp. 239-240. 
teve que ser reforçada pelo exército (161). O consulado britânico foi cercado pela multidão e Christie pensou em colocar marinheiros como guardas (162). De fato, sabe-se que só não. o fêz, devido à insistência do próprio cônsul (163) .

A 3 de janeiro o secretário particular de Abrantes e Christie trabalharam na elaboração de um memorandum que servissé como minuta de um acôrdo. O Brasil concordava pagar sob protesto o que o Govêrno Inglês exigia no caso do Prince of Wales e submeteria o assunto Forte ao arbitramento. $O$ Govêrno Inglês estava livre de aceitar ou rejeitar o que seu representante e os brasileiros elaborassem. Também tôda a correspondência sôbre o assunto deveria ser publicada pelo Brasil (164). Foi apenas a 6 de janeiro que Christie apresentou formalmente a nota final sôbre o assunto, datada de 5 do mesmo mês (165). No mesmo dia, Christie, ordenou que Warren soltasse os navios aprisionados (166).

Pode surpreender-nos que o Brasil não tenha também submetido o caso do Prince of Wales ao arbitramento internacional como Christie queria (167). Vimos que após o comêço das: represálias, Christie expressara o desêjo de ver as questões ar-

(161). - João Manuel Pereira da Silva, Memórias do meu tempo, 2 vols. (Rio de Janeiro (1895?), I, 311, daquí por diante referido como Pereira da Silva, Memórias; Consanção de Sinimbú a D. Pedro II, Rio de Janeiro, 4 de janeiro de 1863, "“o espírito público acha-se muito excitado"), Arquivo MIP, Maço CXXXIII, Doc. 6546; No dia 5 de janeiro foi escrito o opúsculo Questão anglo-brasileira. Panfleto. A pirataria inglêsa e o Brasil. Por um brasileiro (Rio de Janeiro, 1863) na qual é perguntado se Christie "autor de tôda nossa vergonha e humilhação, não se acha no interior desta mesma cidade e não passeia sobranceiro e tranqüilo por onde quer?" (p. 22). "Livre-me Deus, porém, de que alguém queira enxergar em minhas palavras a menor concitação a qualquer movimento ou plano tumultuário". (pp. 30-31). S'ôbre a data do escrito, vide p. 29.

(162). - Christie a Russell, Rio de Janiero, 8 de janeiro de 1863, extrato. N. ${ }^{\circ}$ 72, "Correspondence", Sessional Papers, p. 240; Christie a Thomas Hollocombe, Rio de Janeiro, 8 de janeiro de 1863, incluído em Christie a Russell, Rio de Janeiro, 8 de janeiro de 1863. N.o 72, ibid., p. 270.

(163). - Vianna a Wanderley, 8 de janeiro de 1863. Encontrado em Wanderley Pinto, Cotegipe e seu tempo; primeira fase, 1815-1867, in Biblioteca Pedagógica Brasileira, "Brasiliana”, Sér. 5, vol. LXXXV (São Paulo, 1937), p. 679 .

(164). - Memorandum of basis of arrangement, 3 de janeiro de 1863, incluído em Christie a Russell, Rio de Janeiro, 8 de janeiro de 1863 . N. ${ }^{\circ} 72$, "Correspondence", Sessional Papers, 1863, LXXIII, 265-266.

(165). - Christie a Russell, Rio de Janeiro, 8 de janeiro de 1863, extrato. N.o 72 , ibid., p. 241; Abrantes a Christie, Rio de Janeiro, 5 de janeiro de 1863. Relatório, 1863, Anexo I, pp. 148-149.

(166). - Christie a Warren, Rio de aneiro, 6 de janeiro de 1863, incluído em: Christie a Russell, Rio de Janeiro, 8 de janeiro de 1863 . N:o 72, "Cor-" respondence", Sessional Papers, 1863, LXXIII, 267.

(167). - Christie a Russell, Rio de Janeiro, 8 de janeiro de 1863, extrato. N. 072 , ibid., p. 261 . 
bitradas (168) e, quando Abrantes solicitou informações sôbre se isso incluia mesmo o caso do Prince of Wales que o Brasil admitira prèviamente pagar as indenizações se forçado a fazêlo, Christie respondeu que sim (169). Entretanto, o Brasil concordou em pagar o que lhe era exigido sem apelar para qualquer arbitragem. Tem se dito que o Brasil não considerava próprio aborrecer qualquer árbitro com questões de dinheiro -- em contraste com questões de honra - mas pode-se perguntar se não estaria o Brasil preparando base legal para suas ações futuras (170).

Em todo caso, nem tôdas as fontes de conflito haviam sido eliminadas. Christie encontrou oportunidade para outro protesto surdo ao ler a carta de Abrantes para o Ministro brasileiro em Londres, Francisco Ignácio de Carvalho Moreira (1815-1906), o último Barão do Penedo. A carta informava ao Ministro das ocorrências do Rio e o mandava agir de acôrdo com o acôrdo de 5 de janeiro; não era a respeito disto que Christie se queixava mas, Abrantes foi mais longe ao dizer que uma vez que as interceptações e buscas eram feitas em águas brasileiras, o Govêrno Brasileiro tinha direito a exigir da Inglaterra

"uma satisf̣ação condigna por essa violação da nossa soberania territorial, [e tambẻm]... o direito de reclamar indenização pelos prejuízos que resultaram das: presas feitas pelos navios de guerra inglêses" (171).

Christie explodiu. Protestou que não se tinha feito menção nas notas datadas de 5 de janeiro a favor de nenhum direito do Brasil de exigir satisfações, e salientou que estas notas eram a única base para acôrdo (172). Abrantes concordou

(168). - Christie a Abrantes, Rio de Janeiro, 1 de janeiro de 1863, incluido em Christie a Russell, Rio de Janeiro, 8 de janeiro de 1863 . N.o 72, ibid., p. 261.

(169). - Abrantes a Christie, Rio de Janeiro, 2 de janeiro de 1863. Relatório, 1863, Anexo I, p. 143; Christie a Abrantes, Rio de Janeiro, 2 de janeiro de 1863, incluído em Christie a Russell, Rio de Janeiro, 8 de janeiro de 1863. N.० 72, "Correspondence" Sessional Papers, LXXIII, 264.

(170). - Pereira da Silva, Memórias, I, 313; Oliveira Lima, o Império, p. 215.

(171). - Abrantes a Moreira, Rio de Janeiro, 8 de janeiro de 1863. Relatório, 1863, Anexo I, pp. 155-156.

(172). - Christie a Abrantes, Rio de Janeiro, 9 de janeiro de 1863, incluído em Christie a Russell, Rio de Janeiro, 9 de janeiro de 1863. N.० 74, "Correspondence", Sessional Papers, 1863, LXXIII, 273; Christie a Abrantes, Rio de Janeiro, 8 de janeiro de 1863, incluído em Christie a Russell, Rio de Janeiro, 8 de janeiro de 1863, extrato. N.o 72, ibid., p. 270 ;Abrantes a Christie, Rio de Janeiro, 11 de janeiro de 1863. Relatório, 1863, Anexo p. 158; Christie a Abrantes, Petrópolis, 18 de janeiro de 1863. Thid., p. 161 (não na "Correspondence"). 
'que de fato não havia outro registro de acôrdo e acrescentou que, por causa disso mesmo, o pedido de satisfações não poderia ser excluído. Declarou, também, que o Govêrno Brasileiro não tinha aquiescido voluntàriamente às exigências britâricas e assim não concordara com os têrmos do ultimatum. Agira forçado pelas represálias, tendo agora o direito de pedir satisfações (173). Em outras palavras, era agora a vez do Brasil passar à ofensiva.

Transferiu-se, portanto, o campo de batalha para a Inglaterra, onde as novas relações entre os dois antagonistas encontravam terreno apropriado. O Ministério das Relações Exteriores britânico aprovara inteiramente as medidas tomadas por Christie e aceitara o acôrdo estabelecido em 5 de janeiro. $\mathrm{Na}$ questão do Forte, o Govêrno Britânico aceitou como árbitro o rei dos Belgas, como o Brasil sugerira (174). A decisão do árbitro foi a de que as ações das autoridades brasileiras não podiam ser consideradas como ofensivas à Marinha Britânica (175).

Começou, então, uma correspondência importante entre Carvalho Moreira e Russell. O ministro brasileiro informou a Russell que tinha sido autorizado a pagar sob protesto qualquer soma que o Govêrno Inglês exigisse no caso do Prince of Wales (176). Russell replicou que o Govêrno Britânico informaria a Carvalho Moreira a soma quando fôsse determinada e que seu govêrno considerava a questão resolvida e que "não estava disposto a discutir os têrmos do protesto" (177).

$\mathrm{Na}$ sua nota de 26 de fevereiro, Carvalho Moreira incluiu um cheque para o pagamento da soma estipulada e novamente voltou ao assunto do protesto. Repetiu que o Govêrno Brasileiro recusava-se a admitir qualquer direito por parte do Govêrno Inglês e que incluira o cheque exclusivamente como conseqüência dos

\footnotetext{
(173). - Abrantes a Cristie, Rio de Janeiro, 30 de janeiro de 1863. Relatório, 1863, Anexo I, pp. 169-170.

174). - Abrantes a Christie, Rlo de Janeiro, 7 de janerio de 1863. Mbid., p. 154; Russell a Moreira, Forelgn Office, 12 de fevereiro de 1863. N.0 79, "Correspondence", Sessional Papers, LXXIII, 277.

(175) .- Decision of His Majesty the King of the Belgians. "Despatch from Lord Howard de Walden, transmitting the Decision... (Brussells, June 22, 1863)", Readex Microprint, ed. Edgard L. Erickson, British Sessional Papers, L-C 26 de Junho de 1863 (3187) LXXIII, 361-362; Laudo de S. M. - Rei dos Belgas. Aditamento ao relatório da Repartição dos Negócios Estrangeiros... 1863 (Rlo de Janeiro, 1864) Anexo I, pp. 18-19.

(176). - Carvalho Moreira a Russell, Londres, 9 de fevereiro de 1863. Relatório, Anexo I, pp. 172-173.

(177). - Russell a Carvalho Moreira, Roreign Office, 12 de fevereiro de 1863. N.0 79, "Correspondence", Sessional Papers, 1863, LXXIIr, 277.
} 
 \\ "procedimentos ilegais e violências cometidas"}

pelos inglêses em águas brasileiras. Entretanto, reservava-se o direito de exigir satisfações pela violação de águas brasileiras pelos navios de guerra britânicos (178).

Russell ainda parece ter ignorado, mesmo nesta ocasião, a direção para a qual o ministro brasileiro conduzia o assunto. Respondeu à nota de Carvalho Moreira, discutindo as bases das exigências britânicas e ignorando o protesto brasileiro (179). Carvalho Moreira, então, salientou que de acôrdo com o uso comum, quando um govêrno protesta contra as ações de outro, êste último deve reconhecer formalmente o recebimento de tal protesto (180). Russell então, em uma nota de apenas quatro linhas, acusou o recebimento do protesto (181).

Dois meses mais tarde (181a), depois de consultar o Govêrno Brasileiro, Carvalho Moreira submeteu a Russell uma nova nota. Tratava, em primeiro lugar, da maneira com que as represálias tinham sido conduzidas. De 31 de dezembro a 6 de janeiro o pôrto do Rio fôra virtualmente bloqueado. Enquanto o navio almirante permanecia no pôrto e os britânicos

(178). - Carvalho Moreira a Russell, Londres, 26 de fevereiro de 1863, Relatório, 1863, Anexo I, pp. 174-175.

(179). - Russel a Carvalho Moreira, Foreign Office, 28 de fevereiro de 1863. N.* 2, "Further Correspondence Respecting the Plunder of the Wreck of the British Barque 'Prince of Wales' (in continuation of correspondence presented to Parliement February 26, 1863)", Readex Microprint, ed. Edgar L. Erickson, British Sessional Papers, L-C 2 de março de 1863 (3096), LXXIII, 294.

(180). - Carvalho Moreira a Russell, Londres, 2 de março de 1863. Relatório, 1863, Anexo I, p. 177.

(181). - Russell a Carvalho Moreira, Foreign Office, 4 de março de 1863. N.0 4, "Further Correspondence Respecting the Plunder of the Wreck of the British Barque 'Prince of Wales'; and the Ill-treatment of the Officers of Her Majesty's Ship 'Forte', (in continuation of correspondence presented to Parliament on the 19th and 26th of February and the 2nd of March, 1863)", Readex Microprint, ed. Edgar L. Erickson, British Sessional Papers. L-C 5 de março de 1863 (3103) LXXIII, 301.

(181a). - Carvalho Moreira hesitou em fazer o que fôra ordenado sem verificar o sentido da ordem. Ele alegava que talvez devesse esperar que a questão do Forte fôsse arbitrada antes de prosseguir com os pedidos brasileiros, Abrantes a Carvalho Moreira, Reservado, Rio de Janeiro, 24 de março de 1863. Arquivo Itamaratí, 410-5-93e; D. Pedro II a Abrantes, 21 de março de 1863. Arquivo MIP, Maço CXXXIII, Doc. 6545, N.o 42. D. Pedro dizla que "Carvalho Moreira mostra-se assustado com o resultado da negociação". Vide também ibid. N.o 30. O interêsse do imperador na questão, até ao ponto de alterar as notas de Abrantes tanto na forma como substantivamente, é revelado no mesmo documento, N.os 9, 21, 23 e 49. No N.o 16 (sem data) êle escreveu a Abrantes: "mande para eu ver qualquer resposta sua que ponha têrmo com palavras curtas e enérgicas à chicana do Christie". Vlde também o Dlário de D. Pedro II, Maço XXXV, Doc. 1055, mês de dezembro de 1862, passim. 
consideravam o desembarque de fuzileiros no solo brasileiro, vasos inglêses caçavam navios mercantes brasileiros em águas brasileiras; tendo cinco dêstes navios sido aprisionados e retidos numa baía brasileira. Estes atos, disse Carvalho Moreira, só podiam ser considerados como atos de guerra, sendo contrários às represálias usadas em tempos de paz. Sugeriu que estas represálias deviam ter sido levadas a efeito fora dos limites da soberania brasileira. Carvalho Moreira sugeriu, então, as bases para que fôssem mantidas relações amigáveis entre os dois países. O Govêrno Britânico deveria exprimir

"o seu pesar pelas faltas que acompanharam as represálias", declarar "que não tivera a.intenção de ofender a dignidade e de violar a soberania territorial do. Império"; e concordara em pagar pelos prejuizos causados com a interceptação dos navios, soma que fôsse decidida por arbitragem" (182).

O Govêrno Brasileiro não deixou alternativa aceitável a. Russell. Desculpar-se pela maneira das represálias, para as quais. êle mesmo tinha dado instruções, ou pagar pelos prejuízos, admitindo assim que a Inglaterra agira mal, era impossivel para. êle. Respondeu que, em primeiro lugar, a questão estava encerrada, não tendo o Brasil direito de reabrí-la. Entretanto, acrescentou que o Govêrno Britânico não tinha

"agido por sentimento inamistoso para com o Imperador, nem por desêjo de agressão ao território de Sua Majestade Imperial".

Acreditava ser esta uma resposta suficiente e satisfatória às. reclamações de Carvalho Moreira (183).

A nota de Carvalho Moreira, data de 25 de maio, foi a final. Chamava a atenção de Russell para a sua (de Moreira) nota de 26 de fevereiro, na qual se reservava o direito de. exigir satisfações. Expressava a sua surprêsa pelo fato de Russell declarar a questão encerrada e negar êsse direito ao. Govêrno Brasileiro. Os pedidos do Govêrno Brasileiro baseavam-se, disse, na série de atos de guerra cometidos quando as

(182). - Carvalho Moreira a Russell, Londres, 5 de maio de 1863. Aditamento. ao relatório da Repartị̧ão dos Negócios Estrangeiros... 1863 (Rio de Janeiro, 1864), Anexo I, pp. 7-8.

(183) . - Russell a Carvalho Moreira, Foreign Office, 19 de maio de 1863. N. 2, "Correspondence with the Minister of Brazil Regarding the Satisfaction Demanded by the Brazilian Government for the Late Reprisals", Readex: Microprint, ed. Edgar L. Erickson, British Sessional Papers, L-C 1 dejunho de 1863 (3166), LXXIII, 308 . 
duas nações estavam em estado de paz. O Ministro do Exterior Inglês, de fato, dizia agora não ter tido a Inglaterra a intenção de ofender ao Imperador e perpetrar ações de agressão.. Mas, não era contra as intenções do Govêrno Inglês, e sim pelos atos praticados por seus agentes, que o Govêrno Brasileiro protestava. Além do mais, não tinha Russell expressado arrependimento pela natureza das represálias; nem mencionara satisfações adeqüadas. O Govêrno Brasileiro não podia imaginar que a Inglaterra recusasse reparar os atos de violência gratuíta praticados contra uma nação amiga, violência que a Inglaterra não toleraria de nenhum poder no mundo. Mas, uma vez que era êste o caso, declarava Carvalho Moreira, nâo ter o Brasil outra alternativa senão declarar a ruptura de relações (184). De acôrdo com seu pedido Carvalho Moreira estava de posse do seu passaporte a 28 de maio (185). A 5 de julho o chargé d'affaires da Inglaterra no Rio pediu o seu (186), sendo que Christie já tinha embarcado em março (187).

O encarregado de negócios juntou a seu pedido de passaporte uma longa nota datada de 6 de julho de 1863, que recebera de Russell. Nela encontramos expressa de modo claro a interrelação das queixas britânicas. Em primeiro lugar, Russell, sintetiza qual o objeto tido em mente pelo Govêrno Britânico ao executar as represálias e declara que apenas sua necessidade - e nunca motivo ulterior - levou a Inglaterra á executá-las. Estende-se, então, sôbre o hábito que tinha o Brasil de ignorar representações do Ministro britânico, e entre estas, principalmente, o pedido inglês de informações a respeito dos "emancipados". Discutiu, também, as queixas mútuas nas comissões mistas, que haviam sido extintas por causa de exigências descabidas brasileiras para que a Inglaterra anulasse decisões antigas e bem conhecidas. Esperava que no futuro, quando as relações fôssem restauradas, o Go-

\footnotetext{
(184). - Carvalho Moreira a Russell, Londres, 25 de maio de 1863. Aditamento ao relatório da Repartição dos Negócios Estrangeiros... 1863 (Rio de Janeiro, 1864), Anexo I, pp. 9-12.

(185). - Russell a Carvalho Moreira, Foreign Office, 28 de maio de 1863 . N. ${ }^{\circ}$, "Correspondence with the Minister of Brazil Regarding the Satisfaction Demanded by the Brazilian Government for the Late Reprisals", Readex Microprint, ed. Edgar L. Erickson, British Sessional Papers, L-C 1 de junho de 1863 (3166), LXXIII, 311.

(186). - W. Cornwallis Eliot a Abrantes, Rio de Janeiro, 5 de julho de 1863. Aditamento ao relatório da Repartição dos Negócios Estrangeiros... 1863 (Rio de Janeiro, 1864), Anexo I, pp. 13-14.

(187). - Wanderley Pinho, Cotegipe e seu tempo; primeira fase 1815-1867, in Biblioteca Pedagógica Brasileira, "Brasiliana", Sér. 5, Vol. LXXXV (São Paulo, 1937), 682 .
} 
vêrno Brasileiro se conduzisse com mais cortezia (188). Assim, quase dois anos depois do dia em que naufragara o navio Prince of Wales nas costas solitárias de Albardão, aquêle naufrágio foi pela primeira vez ligado oficialmente às outras ofensas sentidas pela Inglaterra.

Não é nossa intenção determinar se, nestas queixas, encontra-se a causa das ações da Inglaterra. Entretanto, um exame da natureza dos incidentes que tiveram lugar durante $1861 \mathrm{e}$ 1862, combinado com um estudo da diplomacia que se baseou neles, parece demonstrar claramente que não foram êstes incidentes que moveram a Inglaterra.

Robert Cecil criticou as represálias como dependendo de

$$
\begin{aligned}
& \text { "acusações baseadas em bagatelas testemunhadas por } \\
& \text { um cônsul louco e três marinheiros bêbedos" (189). }
\end{aligned}
$$

Mas, mesmo que aceitemos o testemunho de Vereker e dos oficiais do Forte, ainda parece duvidoso que as represálias fôssem um resultado inevitável. Os britânicos acusaram as autoridades brasileiras de negligência para punir os responsáveis pelo saque dos restos do naufrágis, ainda que essa negligência limite-se à libertação dos dois prisioneiros suspeitos pelo inspetor do distrito. Pode-se sustentar que as ações do inpertor tornassem seu país sujeito a represálias? Acusaram os britânicos terem as autoridades brasileiras insultado a Marinha de Sua Majestade com o tratamento ministrado aos oficiais do Forte. Pode-se, também, garantir ser insulto, tratamento ainda que rude, dado a estrangeiros vestidos de roupas comuns e incapazes de falar a língua do país onde se encontram? E, mesmo que os oficiais tivessem podido revelar sua identidade aos soldados brasileiros por algum modo incerto, não seria possível terem êstes considerado isso como uma burla para escapar às conseqüências do seu procedimento? Certamente, há muita consistência no argumento de que ambos incidentes eram mero pretexto para o prosseguimento da luta que há muito se travava entre os dois antagonistas.

Este argumento é reforçado pelo caso Saumarez. Não só tinha o Ministro britânico sèriamente considerado o seu uso

\footnotetext{
(188). - Russell a Eliot, Foreign Office, 6 de junho de 1863. "Instructions Addressed to Her Majesty's Chargé d'Affaire in Brazil, Respecting the Suspension of Diplomatic Relations with Great Britain, Readex Microprint, ed. Edgar L. Erickson, British Sessional Papers, L-C 15 de junho de 1863 (3175), LXXIII, 315-316.

(189). - Discurso de Rober Cecil, Câmara dos Comuns, 6 de março de 1863. Hansard, CLXIX (1863), 1158.
} 
como base para reclamações ao Govêrno Brasileiro, revelandobusca de incidentes pelos britânicos, como expressa claramen-. te a atitude britânica naquele tempo. Nele está implícito o. conceito de que o sistema judicial brasileiro era inferior ao inglês e inadeqüado para zelar pelos direitos dos súditos do Govêrns Inglês. Não é isto base para extra-territorialidade?. Seria coincidência que o Tratado de Tientsin com a China,. que estabelecera firmemente a extra-territorialidade lá, tives-se precedido o naufrágio do Prince of Wales de apenas três anos? (190). Christie mostrava seu desprêzo pela justiça brasileira. an dizer

"não pode-se esperar que o Govêrno de Sua Majesta-. de dê grande valor a qualquer medida judicial do Brasil" (191).

Certamente a crença de Christie nos direitos inglêses de domínio sôbre o Brasil aparece quando revela que as represálias nunca teriam tido lugar se o Brasil fôsse "mais modesto e respeitoso". (192). O caso Saumarez, então, é ao mesmo tempo uma amostra clara da convicção inglêsa de superioridade e, também, evidência do desêjo britânico de afirmar preeminência .

Por outro lado, a exigência brasileira de satisfações por parte do Govêrno Inglês não era necessária em face do acontecido. Não sendo as represálias prática comum, sua vítima está sempre livre de fazer contra elas o que bem entender (193). O Brasil, numa éra de convenções diplomáticas, arriscou uma guerra. Suas ações foram, provàvelmente, determinadas pela pressão do orgulho nacional ferido, pois o nacionalismo que varreu a civilização ocidental no século XIX não deixou o Brasil imune (193a). Mas a fanfarronada brasileira não pre-

\footnotetext{
(190) . - George Williams Keeton, The Development of Extraterritoriality in China,.. 2 vols. (Londres, 1928), apêndice 30, I, 312-314.

(191). - Christíe a Russell, Rio de Janelro, 6 de novembro de 1862 . N.0 64, "Correspondence", Sessional Papers, 1863, LXXIII, 226.

(192). - Christie, "Introduction", p. xxx.

(193). - Evelyn Speyer Colbert, Retaliation in International Law (Nova York; 1948), pp. 76 e 94.

(193a). - Vide publícaçôes como o govêrno inglês on a lógica do canhão. Hontem (isto é, anteceđentes) (Rio de Janeiro, 1863); Opúsculo sôbre a questão anglo-brasileira (Rio de Janeiro, 1863); Questáo anglo-brasileira. Panfleto. A pirataria inglêsa e o Brasil. Por um brasileiro (Rio de Ja-. neiro, 1863); Miguel Vieira Ferreira, A questao anglo-brasileira. Opúsculo (Rio de Janeiro, 1863); Bosquejo analítico àcêrca da questão anglobrasileira (Rio de Janeiro, 1863); Brasil e Inglaterra: breve comparação entre as duas naçóes. A propósito da questáo anglo-brasileira. Folheto * dedicado aos brasileiros (Rio de Janeiro, 1863). O terceiro dêstes dizía :
} 
- cisou ser provada, e a decisão do rei dos Belgas em favor do Brasil deu à Inglaterra a oportunidade de honrosamente restaurar as relações diplomáticas com o Brasil em 1865, mais ou rienos de acôrdo com as exigências brasileiras (194). .

O naufrágio do Prince of Wales, o tratamento dado aos oficiais do Forte, e a exigência de reconhecimento oficial de Saumarez, tudo indica e leva à conclusão de ter sịdo a Inglaterra levava às represálias por algum motivo menos aparente. Que rıão pôde intimidar o Brasil com as suas ações ficou bem claro com a final ruptura de relações diplomáticas. Os laços políticos que outrora ligavam o Brasil à Inglaterra, finalmente, foram *quebrados (195) .

\title{
RICHARD GRAHAM
}

\author{
da Universidade do Texas
}

que "O nosso pavilhão está rôto, despedaçado e mergulhado na lama do opróbrio... E vós, governantes brasileiros, cruzais os braços...? Dizei francamente, e que todos ouçam: 'O Brasil é uma colônia da Inglaterra"” (p. 10).

-(194). - Raul Adalberto de Campos, ed. Relações diplomáticas do Brasil contendo os nomes dos representantes diplomáticos do Brasil no estrangeiro e os dos representantes diplomáticos dos diversos países no Rio de Janeiro de 1808 a 1912 (Rio de Janeiro, 1913), p. 177.

${ }_{4}(195)$. - Depois de ter escrito êste artigo o autor fêz pesquisas em arquivos brasileiros com a ajuda de uma bôlsa de estudos da social Science Research Council: Nenhum fato foi descoberto, todavia, que alterasse as conclusões dêste artigo. No Arquivo do Itamaratí, CF 410-5-93, se acha parte da correspondência citada. Informações de algum interêsse descobertas durante êste período de pesquisa se acham nas notas 13, $24,25,27,146 a, 159 a, 161,181$ a e 193a. 
BIBLIOGRAFIA.

\section{AUXílio BIBLIOGRÁFICO.}

Temperley, Harold, e Lillian M. Penson, A Century of Diplomatic Blue Books, 1814-1914. (Cambridge, 1938) :

FONTES PRIMÁRIAS: COLECón DE DOCUMENTOS.

Brasil. Repartição dos Negócios Estrangeiros. Aditamento ao relatório... 1863 (Rio de Janeiro, 1864), anexo I.

Brasil. Repartị̧ão dos Negócios Estrangeiros. Relatório, 1863 (Rio de Janeiro, 1863), anexo I.

British and Foreign State Papers, LIV (1863-1864) (Londres, 1869).

Grã-Bretanha. Câmara dos Comuns. British Sessional Papers, LXXIII (1863), Readex Microprint, ed. Edgar L. Erickson.

Grã-Bretanha. Parlamento. Hansard's Parliamentary Debates, 3rd series, CLXIX (fevereiro-março de 1863) (Londres, 1863).

\section{FONTES PRIMÁRIAS. MEMóRIAS.}

Christie, William Dougal, "Introduction", The Brazil Correspondence in the Cases of The "Prince of Wales" and Officers of the "Forte" (Reprinted from the Papers Laid before Parliament); with an Introduction Telling Some Truth about Brazil (Londres, 1863).

Christie, William Dougal, Notes on Brazilian Questions (Londres, 1865).

Pereira da Silva, João Manuel, Memórias do meu tempo, 2 vols. (Rio de Janeiro, 1895?), I.

FONTES SECUNDÄRIAS (LIVROS).

Calmon, Pedro, O Marquês de Abrantes (Rio de Janeiro, 1933). Campos, Raul Adalberto de, ed. Relações diplomáticas do Brasil contendo os nomes dos representantes diplomáticos do Brasil no estrangeiro e os dos representantes diplomáticos dos diversos países no Rio de Janeiro de 1808 a 1912 (Rio de Janeiro, 1913).

Colbert, Evelyn Speyer, Retaliation in International Law (Nova York, 1948).

Devoto, Juan E. Pinel e Alcira Ranieri de Pinel Devoto, Historia de la Republica Oriental de Uruguay, 1830-1930) (Montevidéu, 1945). 
Keeton, George Williams, The Development of Extraterritoriality in China, 2 vols. (Londres, 1928), Appendix 30, I, 312314.

Manchester, Alan K., British Preëminence in Brazil, Its Rise and Decline; A Study in European Expansion (Chapel Hill, 1933).

Medonça, Renato, Um diplomata na côrte de Inglaterra; o Barão do Penedo e sua época in Biblioteca Pedagógica Brasileira, "Brasiliana", Série 5, vol. CCXIX.

Oliveira Lima, Manuel de, História diplomática do Brasil: o reconhecimento do império (Rio de Janeiro, 1901?).

Oliveira Lima, Manuel de, O império brasileiro, 1822-1889 (São Paulo, 1927?).

Pinho, Wanderley, Cotegipe e seu tempo; primeira fase, 18151867 in Biblioteca Pedagógica Brasileira, "Brasileira", Série 5, vol. LXXXV (São Paulo, 1937).

\section{FONTES SECUNDARIAS (ARTIGOS).}

Barnett, Richard, "William Dougal Christie", Dictionary of National Biography, ed. Leslie Stephen, X (Londres, 1887), 288-289.

Langer, William L. "The Next Assignment", American Historical Review, LXIII (janeiro de 1958), 283-304. 